\title{
Real world treatment patterns in the neurogenic bladder population: a systematic literature review
}

\author{
Ashley Jaggi, Francis Fatoye \\ Department of Health Professions, Manchester Metropolitan University, Manchester, UK \\ Contributions: (I) Conception and design: All authors; (II) Administrative support: All authors; (III) Provision of study materials or patients: A Jaggi; \\ (IV) Collection and assembly of data: All authors; (V) Data analysis and interpretation: All authors; (VI) Manuscript writing: All authors; (VII) Final \\ approval of manuscript: All authors. \\ Correspondence to: Ashley Jaggi, BSc. Department of Health Professions, Faculty of Health, Psychology and Social Care, Manchester Metropolitan \\ University, Birley Fields Campus, Bonsall Street, Manchester, UK. Email: ashley.jaggi@stu.mmu.ac.uk.
}

\begin{abstract}
Myriad treatment modalities are available for neurogenic bladder (NGB) including behavioral therapies, oral pharmacotherapy, catheterization and surgical procedures. Little is known about how NGB patients are managed in the real world, how well patterns relate to clinical guidelines and how strategies may have changed over time. To address this gap, a systematic review (SR) was conducted using MEDLINE and EMBASE [1996-2017]. The inclusion criteria for studies were: (I) published in English; (II) conducted in human subjects; (III) reporting the treatment patterns/use in NGB; (IV) conducted in a real world setting. A narrative synthesis of results was conducted, comparing the results to current treatment guidelines. Percentage of treatment use was summarized using ranges. Eight studies met the inclusion criteria. Although most studies focused on spinal cord injuries (SCI), study designs and settings were heterogeneous. All data was collected before 2007. The most popular form of oral pharmacotherapy was antimuscarinics, used by 12.6-86.7\% of patients; $0-100 \%$ of patients used catheterization techniques, $2.5-53.1 \%$ used reflex voiding (RV), and $0.2-55 \%$ underwent surgery. A notable amount of patients switched treatments. This SR revealed that numerous strategies have been used to manage NGB throughout the years and there has been a large variance in their use. Whilst there were some discrepancies, most practices matched recommendations made in current guidelines. Ultimately, this SR showed that there is a large gap of epidemiological studies conducted in the field of NGB and the authors felt that available data was insufficient to build a comprehensive picture of treatment patterns. Epidemiological studies using electronic medical records (EMRs) are necessary to advance our understanding of how treatment patterns have changed, and also build a comprehensive picture of how patients are managed in current practice.
\end{abstract}

Keywords: Neurogenic bladder (NGB); therapeutics; epidemiology

Submitted Sep 04, 2017. Accepted for publication Sep 22, 2017.

doi: 10.21037/tau.2017.09.17

View this article at: http://dx.doi.org/10.21037/tau.2017.09.17

\section{Introduction}

Micturition involves passive, low pressure filling of the bladder during the urine storage phase whilst voiding requires coordination of detrusor contraction with urinary sphincter relaxation. The process is controlled by a complex neural control system, involving interaction between the sympathetic, parasympathetic and somatic nervous systems (1). Disturbance to the normal micturition process as a result of neurological damage or disease is known as neurogenic bladder (NGB). The term NGB encompasses a breadth of neurological etiologies including spina bifida, stroke, spinal cord injuries (SCI), multiple sclerosis (MS), and Parkinson's disease (PD) (2). Although patients share the same diagnosis of NGB, they are notably unique in 


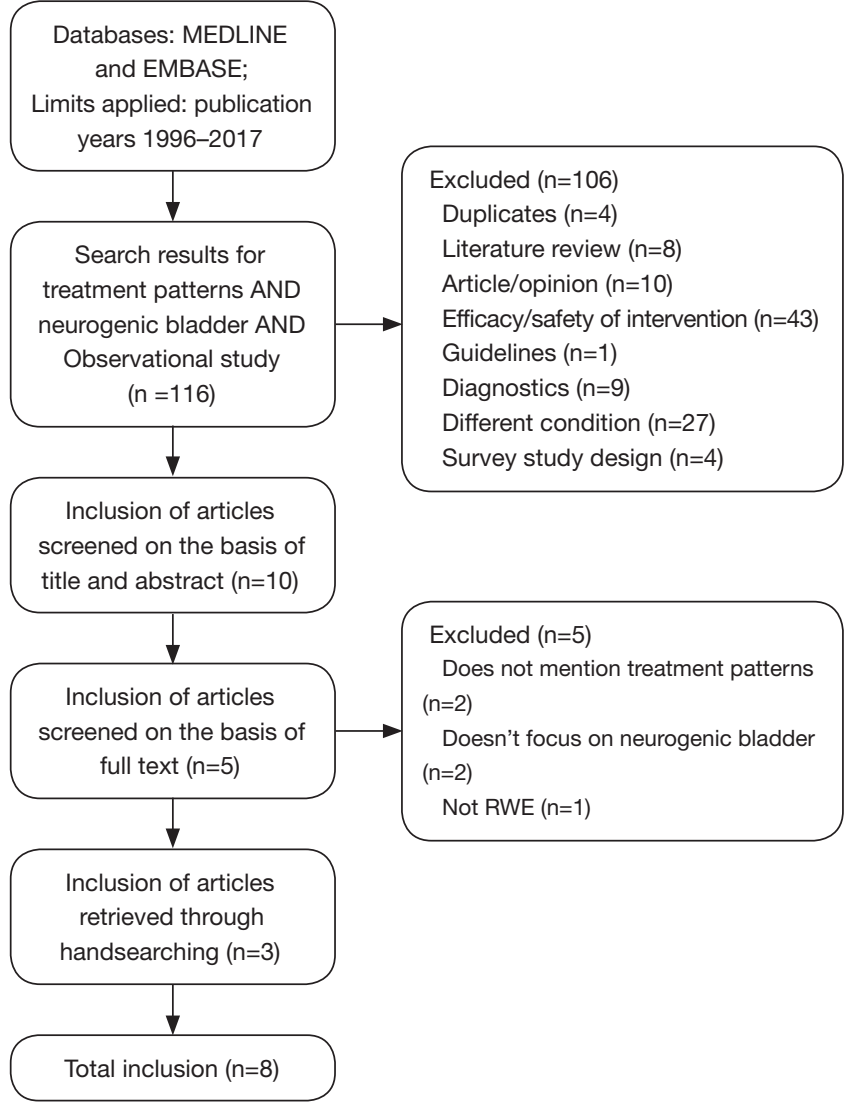

Figure 1 Preferred reporting items for systematic reviews and meta-analyses (PRISMA) flow diagram.

urological symptom and risk profile due to the difference in underlying condition (including stage and severity of disease) and location of neurological lesion.

This considerable heterogeneity compounds the availability of a single optimal medical therapy, meaning that treatments are often wide-ranging and individualized to the particular patient (3). Myriad treatment modalities can be employed including behavioral therapies, oral pharmacotherapy, catheterization and surgery. Four key aims outlined by the European Association of Urology (EAU) that are of paramount importance when selecting treatments are protection of the upper urinary tract, improvement of urinary continence, restoration of the lower urinary tract function and improvement of patient quality of life (QoL) (4).

Despite the availability of clinical guidelines, a survey conducted in the Netherlands found that " $18 \%$ of urologists used the EAU guidelines on NGB frequently, 35\% did so occasionally and $47 \%$ did not use them at all" (5). This systematic review (SR) aims to collate evidence on the management strategies that are employed in the real world and determine whether practices are in concordance with prominent NGB clinical guidelines. This research can act as an important preliminary step in influencing future guideline recommendations to reflect what is working for physicians in the real world. This research also demonstrates how prescribing patterns in NGB may have changed over time. This article aims to describe the treatment patterns and management strategies of NGB in the real word.

\section{Methods}

\section{Eligibility criteria}

(I) Patients with any neurological condition, e.g., spina bifida, stroke, SCI, MS, PD;

(II) Studies that measure treatment use e.g., percentage use, duration of use, treatment switching, combination use;

(III) Real world studies, including both retrospective or prospective: cohort, case-control, cross-sectional and chart review.

During the pilot search, no studies were retrieved that focused solely on adults therefore the search was expanded to include subjects of any age.

\section{Search strategy}

This SR was conducted according to the preferred reporting items for systematic reviews and meta-analyses (PRISMA) guidelines (Figure 1) (6).

A search was run on 15 th February 2017 using a combination of free-text words and medical subject headings in MEDLINE ${ }^{\circledR}$, and EMBASE $^{\circledR}$ (Table S1). Limits were applied for studies published between the years of 1996-2017. Eligibility assessment was conducted in two stages. In the first stage, an independent reviewer (Ashley Jaggi) screened titles and abstracts for alignment with pre-defined inclusion and exclusion criteria (Table 1). Ten percent of included papers were cross-examined by a second independent (Francis Fatoye) reviewer. In the second stage, full versions of the included texts, acquiescent with inclusion criteria, were screened by both reviewers. Any disagreements were mediated by discussion.

\section{Data collection and extraction}

Information on the study design, patient characteristics, 
Table 1 Inclusion and exclusion criteria

Criteria
Inclusion criteria
Published in English
Includes human subjects
Reporting the treatment patterns/use in NGB
Conducted in a real world setting
Exclusion criteria
Non-English publications
In vitro, pre-clinical or animal studies
Randomized controlled trials, SRs, case-report/series,
editorials, questionnaires, letters, commentaries, legal cases,
newspaper articles or patient education materials

NGB, neurogenic bladder; SRs, systematic reviews.

and treatments in NGB was extracted using a piloted data extraction form.

\section{Summary measures}

Treatment patterns were descriptively summarized using narrative review. Percentage of treatment use was summarized using ranges.

\section{Results}

A total of 116 publications were yielded. After screening titles and abstracts and removing additional duplicates (ProQuest Dialog ${ }^{\circledR}$ removes most duplicates), 10 articles were retrieved, and the full texts were reviewed. Based on full text review, five papers were excluded for reasons according to the study protocol. A total of eight papers were included for analysis. Three papers were obtained from hand searching (7-14).

\section{Study and patient characteristics}

Overall, there were 47,706 patients with NGB, of these, $43.8 \%$ were male and the mean age was 42.8 . The majority of included patients [46,271] were from two studies. Despite being published at separate times (2009 and 2011), these studies included the same cohort of patients (using the same inclusion criteria and database). Patients included in these studies had mixed underlying neurological conditions including MS, SCI, PD, paralytic syndrome, cerebral palsy and spina bifida. What differentiates the two studies is the 2011 study identified separate sub-cohorts for SCI and MS, including 4,168 and 9,315 patients respectively. Most of the included studies (62.5\%) focused on patients with SCI (or included a subgroup), at various levels of neurological injury and varied time since injury. Across the studies, there were a total of 5,182 patients with SCI. One study focused on spina bifida patients, including 421 individuals. The earliest period of data collection began in 1984 and the most recent ended in 2007 (Table 2).

\section{Treatment patterns}

\section{Oral pharmacotherapy}

Five out of the eight included studies included data on the use of oral pharmacotherapy. Three studies included information on antimuscarinic drug use, which spanned between 12.6-86.7\%. Results from two studies demonstrated a range of $12.6-39 \%$ patients using oxybutynin.

The lowest recorded antimuscarinic drug use was reported by Lemelle et al., where $12.6 \%$ of spina bifida patients used oxybutynin regularly. The percentage of patients receiving antimuscarinics was almost double in the study by Chia-Cheng et al., where it was used by $26 \%$ of SCI patients with neurogenic detrusor overactivity (NDO). Manack et al. [2011] reported much higher percentages, with $71.5 \%$ of patients in the NGB cohort, $80.9 \%$ in the SCI cohort and $86.7 \%$ in the MS cohort using this treatment. A prescription of an antimuscarinic drug (rather than any form of bladder management method), was one way in which a patient could be included into the study by Manack et al. [2011], which could explain why percentage use was higher in this study, than other studies in this review. The highest use of oxybutynin of all publications was also recorded in this study (39\%), followed by tolerodine (36.9\%). El-Masri et al. mention that antimuscarinics were administered to those with NDO, but percentage use is not delineated.

El-Masri et al. and Chia-Cheng et al. reported the use of alpha-blockers; however, neither of the authors communicated the names of drugs. In the study by ChiaCheng et al., the most prevalent drugs amongst SCI patients with NDO were alpha-blockers, used by $33 \%$ of individuals. Alpha-blockers were administered to SCI patients with marked bladder outlet obstruction (BOO) in the study by El-Masri et al., but as with antimuscarinic use, percentage 
Table 2 Summary of study and patient characteristics of included studies

\begin{tabular}{|c|c|c|c|c|}
\hline Study & $\begin{array}{l}\text { Data collection } \\
\text { period }\end{array}$ & Study design & Location & Patient sample characteristics \\
\hline $\begin{array}{l}\text { Anson } \\
{[1996]}\end{array}$ & Not reported & $\begin{array}{l}\text { Prospective } \\
\text { (longitudinal) }\end{array}$ & USA & $\begin{array}{l}348 \text { individuals, } 33 \% \text { aged over } 18 \\
\text { mean age: } 36.6,82 \% \text { male and } 18 \% \\
\text { female, } 80.2 \% \text { Caucasian }\end{array}$ \\
\hline $\begin{array}{l}\text { Chia- } \\
\text { Cheng } \\
\text { [2012] }\end{array}$ & 2006-2008 & $\begin{array}{l}\text { Retrospective } \\
\text { (cross- } \\
\text { sectional) }\end{array}$ & Taiwan & $\begin{array}{l}165 \text { patients, mean age: } 54,64 \% \text { male } \\
\text { and } 46 \% \text { female }\end{array}$ \\
\hline $\begin{array}{l}\text { Drake } \\
\text { [2005] }\end{array}$ & 1990-1996 & $\begin{array}{l}\text { Prospective } \\
\text { (longitudinal) }\end{array}$ & UK & $\begin{array}{l}196 \text { individuals, aged } 15-55 \text {, mean age } \\
57.4,86 \% \text { male and } 24 \% \text { female }\end{array}$ \\
\hline
\end{tabular}

\begin{tabular}{|c|c|c|c|c|}
\hline $\begin{array}{l}\text { El-Masri } \\
\text { [2012] }\end{array}$ & $\begin{array}{l}\text { From } 1984 \text {, } \\
\text { with follow } \\
\text { up ranging } \\
\text { between } 8 \text { and } \\
21 \text { years }\end{array}$ & $\begin{array}{l}\text { Retrospective } \\
\text { (longitudinal) }\end{array}$ & UK & $\begin{array}{l}119 \text { individuals, aged } 16-63 \text {, mean ag } \\
29,83.2 \% \text { males, } 16.8 \% \text { females }\end{array}$ \\
\hline $\begin{array}{l}\text { Lemelle } \\
\text { [2006] }\end{array}$ & 2003-2004 & $\begin{array}{l}\text { Retrospective } \\
\text { (longitudinal) }\end{array}$ & France & $\begin{array}{l}421 \text { individuals, aged } 10-47.5 \text {, mean } \\
\text { age: } 22.1,140 \text { aged } 10-18 \text { and } 281 \\
\text { aged over } 18 ; 55 \% \text { male and } 45 \% \\
\text { female }\end{array}$ \\
\hline
\end{tabular}

\begin{tabular}{|c|c|c|c|c|}
\hline $\begin{array}{l}\text { Manack } \\
\text { [2011] \& } \\
\text { Manack } \\
\text { [2009] } \\
\text { (NGB } \\
\text { cohort } \\
\text { only) }\end{array}$ & $\begin{array}{l}\text { April 1, 2002- } \\
\text { March 31, } \\
2007\end{array}$ & $\begin{array}{l}\text { Retrospective } \\
\text { (longitudinal) }\end{array}$ & USA & $\begin{array}{l}46,271 \text { individuals in NGB cohort, } 9,315 \\
\text { individuals in MS, } 4,168 \text { individuals in } \\
\text { SCl, aged } 0-60+\text {, mean age of NGB } \\
\text { cohort was } 62.5 \text { years, mean ages in } \\
\text { the MS and SCl subcohorts, } 53.2 \text { and } \\
61.9 \text { years respectively. } 43.6 \% \text { males } \\
\text { and } 57.4 \% \text { females in NGB cohort, } \\
31.3 \% \text { male and } 79.7 \% \text { female, } 41.9 \% \\
\text { male and } 59.1 \% \text { female in MS and SCI } \\
\text { subcohorts respectively }\end{array}$ \\
\hline $\begin{array}{l}\text { Weld } \\
\text { [2000] }\end{array}$ & $\begin{array}{l}\text { Years not } \\
\text { reported; } \\
\text { follow up: } 18.3 \\
\text { years since } \\
\text { injury }\end{array}$ & $\begin{array}{l}\text { Retrospective } \\
\text { (longitudinal) }\end{array}$ & USA & $\begin{array}{l}316 \text { individuals, mean age: } 38 \text { years, } \\
99 \% \text { male and } 1 \% \text { females }\end{array}$ \\
\hline
\end{tabular}

Neurological condition and severity

SCI: C0-C4: 19.7\%,

C5-C8: 36.2\%, T1-T11: 29.4\%, T12-S5: $14.7 \%$; years since injury: 1-2 years: $26 \%, 3-5$ years: $25.2 \%$, $6-10$ years: $29.3 \%, 11-15$ years: $12 \%, 15+$ years: $8 \%$

Patients with emergency department visits or hospitalizations for $\mathrm{SCl}$

$\mathrm{SCl}$ for at least 20 years; level of injury: paraplegics with complete $\mathrm{SCl}$ (Frankel grade A, B, or C): $49 \%$; tetraplegics with complete $\mathrm{SCl}$ (Frankel grade A, B, or C): $31.1 \%$; incomplete SCI (Frankel grade E): $18.9 \%$; mean years since injury: 33.26

SCI: paraplegic (two had S3 sacral lesion): $37.3 \%$; tetraplegic: $27 \%$; Frankel grade A: 34\%; Frankel grade B: 4.3\%; Frankel grade C: 7.7\%; Frankel grade D: $18.4 \%$; mean years since injury: 29

Spina bifida (myelomeningocele at the neonatal period, which was treated surgically); ability to move: walk with minor aid: $63 \%$; walk with walking appliance: $3 \%$; wheelchair outside + walk at home: $8 \%$; wheelchair most of time: $26 \%$

MS, [SCl (including paraplegia, quadriplegia, tetraplegia), spina bifida, Parkinson's disease, cerebral palsy, hemiplegia/ hemiparesis, late effects of stroke, other paralytic syndromes, and neoplasm of the spinal cord]

SCI: injury completeness: complete: $14.2 \%$, incomplete: $85.8 \%$; injury level: suprasacral: $85.1 \%$, sacral: $14.9 \%$; mean years since injury: 18.3 years

C, cervical nerves; T, thoracic nerves; SCI, spinal cord injuries; MS, multiple sclerosis; NGB, neurogenic bladder. 
use is not described.

The study by Chia-Cheng et al. was the only one to mention use of cholinergics, where it was used by $15 \%$ of SCI patients with NDO.

\section{Patterns of use with oral pharmacotherapy}

Manack et al. [2011] provides information on patterns of oral drug use, which is not available from the other studies. A total of 7,782 continued on an OAB drug, 10,110 discontinued and did not start, and a further 9,030 stopped and restarted. The average length of time on drug was 209.1 days for the MS subcohort and 195.5 days for the SCI cohort.

\section{Catheterization}

Urinary catheter use varied substantially. Intermittent catheterization (IC) use was reported in six studies, with a range between $0-84 \%$. Indwelling catheterization (IDC) [both indwelling urethral catheterization (IDUC) and indwelling suprapubic catheterization (SPC)] was reported in four studies, with a range of $0 \%$ to $100 \%$.

Chia-Cheng et al. reported that catheterization was used by $67 \%$ of patients with NDO as a consequence of SCI, however it is unclear whether catheterization refers to IC or IDC

\section{IC}

Lemelle et al. reported that $71.3 \%$ patients with spina bifida were using IC. Anson et al. and Weld et al. reported much smaller percentages in post-acute phase SCI, with $30.5 \%$ and $29.1 \%$ respectively.

When considering studies with observations at multiple time points, El-Masri et al. reported $27 \%$ of SCI patients using assisted IC immediately before admission to the hospital; however, no patients utilized this method upon admission. During hospitalization, 4-hourly IC was the most utilized method, with $84 \%$ of patients using it at least once. This is the highest report of IC use from all publications. This markedly declined to $15.1 \%$ patients at discharge from hospital. In contrast to El-Masri et al., the use of IC increased by $10.2 \%$ in the study by Drake et al.; from $3.6 \%$ SCI patients in 1990 to $13.8 \%$ in 1996.

The difference in IC use between these two studies could be attributable to the varied follow-up. In Drake et al., changes take place over six years whereas follow up in the study by El-Masri et al. ranged between 8 and 21 years (mean 17.7).
IDC

Weld et al. reported $36.1 \%$ post-acute SCI patients that utilized IDUC and $11.4 \%$ patients had a SPC fitted. In the study by Anson et al., much lower percentages were reported, with $9.8 \%$ that used IDUC and 3.2\% that used SPC. The lowest recorded use of SPC use amongst the publications was one spina bifida patient in the study by Lemelle et al.

Studies with multiple observations seemed to paint a heterogeneous picture of IDC use. Overall, IDUC use substantially decreased (by 60.6\%) in SCI patients, throughout the duration of the study by El-Masri et al., but the general trend was not a linear decline. SPC use decreased at a much lower rate $(0.8 \%)$ from hospitalization to discharge. In contrast to this, the number of SCI patients utilizing IDUC increased by $1.6 \%$ during the study by Drake $e t a l$., and SPC use increased by $7.2 \%$.

In the study by El-Masri et al., 69\% were managed with IDUC before admission to hospital and this increased to all patients upon admission; $21 \%$ of patients utilized this method at least once during hospitalization. After discharge, 8.4\% patients remained with IDUC. In the study by Drake et al., 12.2\% had IDUC in 1990 and this increased to $13.8 \%$ in 1996.

The first recorded use of SPC was in the study by El-Masri et al. was during hospitalization, where $5 \%$ of patients utilized this method. After discharge, it was used by $4.2 \%$ of patients. Only 2\% utilized SPC at study entry in the study by Drake $e t$ al., but this increased at a much higher rate than IDUC use, with $9.2 \%$ of patients utilizing this method at study end.

\section{Reflex voiding (RV)}

RV methods can include bladder expression (Credé), straining (Valsalva) and triggered RV (4). In this SR, RV use was reported in four studies, varying from $2.5 \%$ to $53.1 \%$.

RV methods are used by $25 \%$ of SCI patients in the study by Anson et al. and 23\% SCI patients in the study by Weld et al. Although these percentages are close in range, they cannot be directly compared as Anson et al. fail to provide a definition of RV. Weld et al. defines spontaneous voiding as "reflexive voiding with a post-void residual urine of less than $100 \mathrm{cc}$ and a voiding pressure of less than $40 \mathrm{~cm}$ ".

In the study by Drake et al., RV was defined as "leaving $a$ post void residual $<10 \%$ and with no upper tract dilation, with or without prior sphincterotomy or urethral stent". Use decreased by $11.8 \%$ during the study period, from $53.1 \%$ to $41.3 \%$, but it remained the most used method within the study. 
El-Masri et al. did not specifically define RV. A small number of patients (2.5\%) were managed with RV prior to admission and during hospitalization it was used by $16.8 \%$ individuals. It was the most common form of bladder management after patients were discharged from the hospital, where it was utilized by $49.8 \%$ patients.

In the study by Drake et al., straining methods (defined as either Credé or Valsalva) decreased by $8.2 \%$, from $19.4 \%$ to $11.2 \%$. A much lower percentage $(2.6 \%)$ of patients used expression techniques (Credé) at the end of the study by ElMasri et al.

\section{Surgery}

Two authors report use of surgery to manage bladder symptoms. Manack et al. [2009] reports particularly low numbers of bladder augmentation and interstim therapy $(0.2 \%$ and $0.4 \%$ respectively) in NGB patients. This is in contrast to Lemelle et al., where the majority of spina bifida patients $(55 \%)$ were surgically treated. Of these patients, $21.3 \%$ underwent bladder neck surgery, without bladder augmentation (with or without continent diversion), 36\% patients underwent intestinal bladder augmentation (with or without bladder neck procedure) and $28.3 \%$ patients underwent intestinal bladder augmentation in addition to Mitrofanoff (with or without bladder neck procedure).

\section{Other management methods}

In the study by Lemelle et al., $8.3 \%$ of people used pads and $1 \%$ of patients used an uriseath.

\section{Combination use}

\section{Combinations of oral pharmacotherapy}

Manack et al. [2011] reported $8.7 \%$ of patients on a combination of two or more antimuscarinic drugs; $8.3 \%$ were on two drugs, $0.4 \%$ were on three drugs and a negligible amount were on four or more drugs. A similar pattern was seen in the MS and SCI subcohorts; $9.5 \%$ patients in the MS subcohort were on a combination of two or more antimuscarinics, a further $9 \%$ were on two drugs, $0.5 \%$ were on three drugs and only two patients were on four or more drugs. When considering the SCI cohort, $9.2 \%$ patients were on a combination of two or more antimuscarinics, $8.9 \%$ were on two drugs, $0.3 \%$ were on three drugs and no patients were on four of more drugs.

A combination of alpha-blockers and antimuscarinics were given to those with detrusor sphincter dyssynergia (DSD) and autonomic dyssynergia in the study by El-Masri et al. Percentages of combination use were not reported.

\section{Combination of a therapy with catheterization}

Lemelle et al. states that $12.6 \%$ spina bifida patients regularly utilized IC in combination with oxybutynin. $90 \%$ of patients used IC in addition to surgery, including $61 \%$ through a continent neoconduit and $39 \%$ on abdominal wall.

In the study by Anson et al., $11.5 \%$ patients were on a combination of IC and reflex. There is also a report of $3.7 \%$ of patients on some combination of treatments between IC, reflex, IDUC, SPC and self-voiding, but actual combinations are not provided.

\section{Combination of surgical procedures and bladder neck injections}

Lemelle et al. reports $39 \%$ of patients undergoing a combination of surgical procedures to achieve reservoir and neck management in spina bifida patients. The most popular combination of procedures is intestinal bladder augmentation + Mitrofanoff principle + neck closure.

\section{Switching}

Weld et al. mentions that most post-acute SCI patients switched bladder management methods over the course of the study period; with the most prevalent change being from IC to IDUC (percentage is not provided); $14.3 \%$ of patients in the study by Drake et al., and one patient in the study by El-Masri et al. also made this particular switch of treatments.

As in the study by Weld et al., most patients in the study by Drake et al. switched from their original mode of management (62.8\%). However, the most prevalent change in this study was straining to IC $(28.9 \%)$. The most used method in 1990 was RV, and this remained the case in 1996, despite $24 \%$ switching to an alternative form of treatment.

El-Masri et al. also showed a large proportion of patients $(39.5 \%)$ that switched treatments during hospitalization. In contrast to both Weld et al. and Drake et al., the most prevalent switch was IC to sphincterotomy and IDUC to IC.

\section{Discussion}

Selecting optimal treatments and employing appropriate management strategies for NGB patients is integral to improving patients' bladder symptoms and improving QoL. With passing time, clinicians have moved away from techniques associated with higher rates of complications and mortality, thus in recent years, the survival chances of NGB patients have substantially improved (15). This SR revealed that numerous treatments have been used to manage NGB throughout the years and there has been a large variance in their use. 
The most popular oral pharmacotherapy in this SR were antimuscarinics, which are cited as first line therapy for NDO in the National Institute for Health and Care Excellence (NICE), EAU and International Consultations on Incontinence (ICI) guidelines $(4,16,17)$. This conclusion should be viewed with some caution, as many studies in this review did not measure the use of oral pharmacotherapy, instead focusing their attention on other methods of bladder management. It is however well known that NDO is frequently observed in SCI (which $62.5 \%$ of included studies focused on) and antimuscarinics have acted as the primary mode of treatment for a number of years (18).

In the study by Manack et al. [2011], some patients used a combination of two or more antimuscarinics. Based on evidence from a few small clinical trials, the EAU provide a grade $\mathrm{B}$ recommendation, asking physicians to consider a combination of antimuscarinic agents (4,19-21). Other available guidelines do not provide graded recommendations on combination antimuscarinic use.

Invasive forms of management such as bladder augmentation are only employed once more conservative measures have been exhausted. A minority of spina bifida patients do not respond well to conservative treatments thus must undergo surgery to improve bladder functionality (22). Conversely, the one study included in this SR, focusing on spina bifida, reported that the majority of patients underwent surgery. This may be due to a high severity of incontinence in this sample, higher incidence of refractory NGB or a less conservative attitude of physicians towards surgery in France between 2003-2004 (the study period).

Many of the studies in this SR have early periods of data collection therefore, it is perhaps comprehensible that some practices deviated from what is currently considered safe and effective. One example of such variance is the use of the Credé and Valsalva manoeuvres in studies that collected data in the 1980's and 1990's (7,11). In current guidelines, these techniques are contraindicated due to complications including epidydymoorchitis and haemorrhoids $(4,17,23)$.

IDC was also widely used (up to $100 \%$ ) despite the fact that this type of catheterization is associated with an increased risk of urinary tract infection (UTI), and more serious conditions such as bladder cancer $(4,16)$. It is important to remember however, that SCI can result in limited manual dexterity (e.g., in the case of tetraplegia), impeding the ability of intermittent self-catheterization (ICS) (24). The current NICE guidelines recognise that in some instances the choice of management technique is limited by what the patient can manage (16). Furthermore, the latest ICI guidelines suggest that assigning causation of urinary tract damage to IDC may not be accurate, as it is often utilized in patients in whom urinary tract damage has already occurred. Drake sugested that IDC may in fact be protective for the upper urinary tract (25). Although SPC is generally prefered over IDUC, it was used at a much lower rate. This could possibly be because placement of SPC is a more invasive procedure than IDUC (17).

This review had a global geographical scope, thus one may assume that the management methods employed reflect the healthcare system and national guidelines in which the study was conducted. At present, the American Urology Association (AUA) lacks any specific guidelines for the management of NGB. High antimuscarinic use in the two U.S. studies by Manack et al. are in line with other internationally available guidelines, where antimuscarinics are first line therapy for patients with $\operatorname{NDO}(4,16,17)$. In the study by Chia-Cheng et al., conducted in Taiwan, alpha-blockers were the main method of management for NDO, despite Taiwanese NGB guidelines stating there is strong evidence to support the use of antimuscarinics in NDO (26). Their use may indicate patients had retention symptoms, in conjunction to NDO. Alternatively, several small clinical trials have demonstrated efficacy of alphablockers in NDO, which could indicate that clinicians in the real world are making choices in divergence from guideline recommendations $(27,28)$. This notion correlates with results from a survey conducted by Rikken et al., which showed that urologists did not follow guideline recommendations meticulously. Nevertheless, this survey also found that despite not adhering to guidelines, urologists still tended to make choices in accordance with recommendations (5).

Three studies demonstrated notable treatment switching, which could be indicative of the dynamic progression of NGB. Duration of time since injury in SCI can have an impact on bladder compliance that can consequently influence changes in the choice of management strategy (15). Alternatively, treatment switching may demonstrate that a trial and error approach is necessary to establish an optimal treatment regime (29). A number of factors influence the initial choice of management method, including type of NGB, sex, age, hand dexterity and healthcare access (30). In the study by Drake et al., reasons for switching treatments pertained to complications such as functional decline and UTI's (7). Some patients included in this review made their own treatment choices, indicating that individual preference also plays a large role $(7,11,12)$. Current guidelines promote active dialogue between 
the physician and patient/their carer. In particular, NICE guidelines make specific recommendations for education of patients and their carers on the advantages and disadvantages of all available options so they are able to make informed management decisions (16,31).

\section{Methodological limitations}

The sensitivity of the search strategy could have been increased by including search terms for underlying neurological conditions. Additionally, publication bias and inclusion of mixed study designs could have affected the reliability of results.

\section{Conclusions}

Many treatments reported in this review are in line with current guideline recommendations; however, possibly due to the early years of data collection, some divergence was also evident. Due to the small number of studies, varied patient baseline characteristics, and selectiveness in the type of treatments and bladder management methods reported, a representative picture of real world treatment patterns in NGB could not be fully elucidated. Large epidemiological studies using electronic medical records (EMRs) are necessary to advance our understanding in how management strategies have changed over time, understand how patients are managed in current practice, and determine how well patterns relate to clinical guidelines.

\section{Acknowledgements}

None.

\section{Footnote}

Conflicts of Interest: A Jaggi works full-time at Astellas Pharma EU under a Knowledge Transfer Partnership (KTP) with Manchester Metropolitan University (MMU). F Fatoye has no conflicts of interest to declare.

\section{References}

1. Fowler CJ, Griffiths D, de Groat WC. The neural control of micturition. Nat Rev Neurosci 2008;9:453-66.

2. Haab F. The Conditions of Neurogenic Detrusor Overactivity and Overactive Bladder. Neurourol Urodyn 2014;33:S2-S5.
3. Wyndaele J. Conservative treatment of patients with neurogenic bladder. Eur Urol 2008;557-65.

4. Bloc B, Pannek J, Castro-Diaz D, et al. EAU Guidelines on Neuro-Urology. European Association of Urology: Arnhem, The Netherlands, 2017.

5. Rikken B, Blok BFM. Management of Neurogenic Bladder Patients in The Netherlands: Do Urologists Follow Guidelines? Neurourol Urodyn 2008;27:758-62.

6. Liberati A, Altman DG, Tetzlaff J, et al. The PRISMA statement for reporting systematic reviews and metaanalyses of studies that evaluate healthcare interventions: explanation and elaboration. PLoS Med 2009;6:e1000100.

7. Drake MJ, Cortina-Borja M, Savic G, et al. Prospective evaluation of urological effects of aging in chronic spinal cord injury by method of bladder management. Neurourol Urodyn 2005;24:111-6.

8. Manack A, Motsko SP, Jones JK, et al. Medication and Healthcare Utilization of Neurogenic Bladder Patients in a US Claims Database. Neurourol Urodyn 2011;30:395.

9. Manack A, Motsko SP, Haag-Molkenteller C, et al. Epidemiology and healthcare resource utilization of neurogenic bladder patients in a US claims database. Neurourol Urodyn 2011;30:395-401.

10. Chia-Cheng L, Edward Y, Yea-Huei K, et al. Management of Neurogenic Detrusor Overactivity in Patients with Spinal Cord Injury in Taiwan. Pharmacoepidemiol Drug Saf 2012;21:64-5.

11. El-Masri WS, Chong T, Kyriakider AE, et al. Long-term Follow-up Study of Outcomes of Bladder Management in Spinal Cord Injury Patients Under the Care of The Midlands Centre for Spinal Injuries in Oswestry. Spinal Cord 2012;50:14-21.

12. Weld KJ, Dmochowski RR. Effect of Bladder Management on Urological Complications in Spinal Cord Injured Patients. J Urol 2000;163:768-72.

13. Lemelle JL, Guilemin F, Aubert D, et al. A Multi Centre Evaluation of Urinary Incontinence Management and Outcome in Spina Bifida. J Urol 2006;175:208-12.

14. Anson CA, Shepherd C. Incidence of Secondary Complications in Spinal Cord Injury. International Journal of Rehabilitation Research. Int J Rehab Res 1996;19:55-66.

15. Harrison SCW. Managing the Urinary Tract in Spinal Cord Injury. Indian J Urol 2010;26:245-52.

16. NICE. Urinary incontinence in neurological disease:management of lower urinary tract dysfunction in neurlogical disease: National Institute for Health and Clinical Excellence: London, 2012.

17. Apostolidis A, Drake MJ, Emmanuel A, et al. Neurologic 
Urinary and Fecal Incontinence. In: Cardozo P, Wagg

L, Wein A, et al. editors. Incontinence: International Consultation on Urological Diseases. 6th edition. Tokyo: International Consultation on Urological Diseases: 2017;1093-309.

18. Madhuvrata P, Singh M, Hasafa Z, et al. Anticholinergic drugs for adult neurogenic detrusor overactivity: a systematic review and meta-analysis. Eur Urol 2012;62:816-30.

19. Nardulli R, Losavio E, Ranieri M, et al. Combined Antimuscarinics for Treatment of Neurogenic Overactive Bladder. Int J Immunopathol Pharmacol 2012:25;35S-41S.

20. Amend B, Hennenlotter J, Schäfer T, et al. Effective treatment of neurogenic detrusor dysfunction by combined high-dosed antimuscarinics without increased side-effects. Eur Urol 2008;53:1021-8.

21. Horstmann M, Schaefer T, Aguilar Y, et al. Neurogenic bladder treatment by doubling the recommended antimuscarinic dosage. Neurourol Urodyn 2006;25:441-5.

22. Mingin GC, Baskin LC. Surgical Management of the Neurogenic Bladder and Bowel. Int Braz J Urol 2003:29;53-61.

23. Vodusek DB, Boller F. Neurology of Sexual and Bladder Disorders. In: Aminoff MJ, Boller F, Swaab DF. editors.

Cite this article as: Jaggi A, Fatoye F. Real world treatment patterns in the neurogenic bladder population: a systematic literature review. Transl Androl Urol 2017;6(6):1175-1183. doi: 10.21037/tau.2017.09.17
Handbook of Clinical Neurology. Amsterdam: Elsevier, 2015;130:255.

24. Taweel WA, Seyam R. Neurogenic bladder in spinal cord injury patients. Res Rep Urol 2015;7:85-99.

25. Weld KJ, Wall BM, Mangold TA, et al. Influences on renal function in chronic spinal cord injured patients. J Urol 2000;164:1490-3.

26. Kuo H, Chen S, Chou C, et al. Clinical guidelines for the diagnosis and management of neurogenic lower urinary tract dysfunction. Tzu Chi Medical Journal 2014;26:103-13.

27. Yasuda K, Yamanishi T, Kawabe K, et al. The effect of urapidil on neurogenic bladder: a placebo controlled double-blind study. J Urol 1996;156:1125-30.

28. Swierzewski SJ 3rd, Gormley EA, Belville WD, et al. The effect of terazosin on bladder function in the spinal cord injured patient. J Urol 1994;151:951-4.

29. Martinez L, Neshatian L, Khavari R. Neurogenic Bowel Dysfunction in Patients with Neurogenic Bladder. Current Bladder Dysfunction Reports 2016;11:334-40.

30. Taweel WA, Seyem R. Neurogenic Bladder in Spinal Cord Injury Patients. Res Rep Urol 2015;7:85-99.

31. Engkasan JP, Ng CJ, Low WY. Factors Influencing Bladder Management in Male Patients With Spinal Cord Injury: A Qualitative Study. Spinal Cord 2014;52:157-62. 


\section{Supplementary}

Table S1 Search performed in ProQuest Dialog ${ }^{\circledR}$

\begin{tabular}{|c|c|c|}
\hline Set & Searched for & Results \\
\hline S5 & [(S1 AND S2) AND S3] and [pd (19960101-20171231)] & $116^{\#}$ \\
\hline S4 & (S1 AND S2) AND S3 & $128^{\#}$ \\
\hline S3 & $\begin{array}{l}\text { \{(treatment pattern*) OR [standard near/2 (treatment OR therapy OR care)]\} OR MESH.EXACT.EXPLODE ("Standard } \\
\text { of Care") OR EMB.EXACT.EXPLODE ("health care quality") OR EMB.EXACT.EXPLODE ("health care utilization") }\end{array}$ & $870,350^{*}$ \\
\hline S2 & 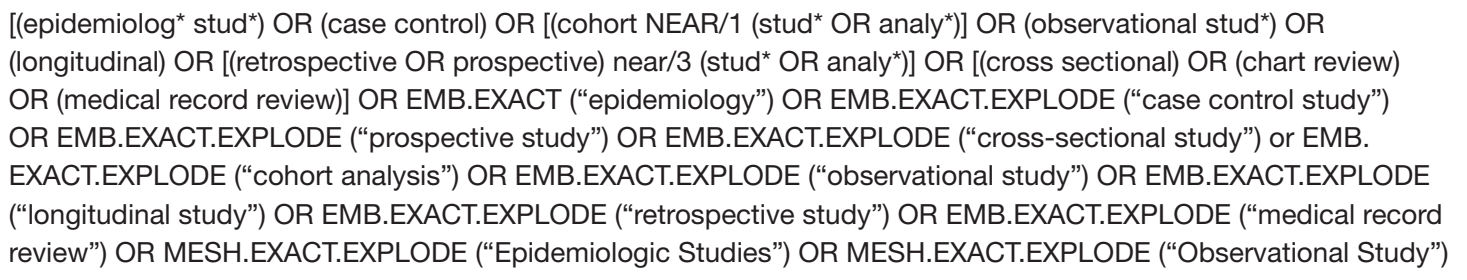 & $7,643,028^{*}$ \\
\hline
\end{tabular}

*, duplicates are removed from the search, but included in the result count. ${ }^{*}$, duplicates are removed from the search and from the result count. 